\title{
Preface: the WinMon.BE 2013 conference: steps towards an efficient and effective offshore wind farm environmental impact assessment
}

\author{
Steven Degraer • Jennifer Dannheim • \\ Andrew B. Gill · Han Lindeboom • \\ Dan Wilhelmsson
}

Published online: 7 May 2015

(C) Springer International Publishing Switzerland 2015

The race for a timely combat of climate change through the reduction of greenhouse gasses such as carbon dioxide has pushed renewable energy developments to a higher echelon. At present, wind is one of the most profitable sources of exploitable renewable energy. Wind farms are popping up at many places worldwide. Their expansion on land, however is constrained, because sites where wind farms do not conflict with the high-quality environmental standards of the local community are limited. Being uninhabited, the marine environment offers a vast area for wind farm development.

Being uninhabited, however, does not equal not being subject to impact. The sea and oceans host rich

Guest editors: Steven Degraer, Jennifer Dannheim, Andrew B. Gill, Han Lindeboom \& Dan Wilhelmsson / Environmental impacts of offshore wind farms

S. Degraer $(\bowtie)$

Royal Belgian Institute of Natural Sciences (RBINS), Operational Directorate Natural Environment, Marine Ecology and Management, Brussels, Belgium

e-mail: steven.degraer@naturalsciences.be

J. Dannheim

Alfred Wegener Institute, Helmholtz Centre for Polar and Marine Research, Bremerhaven, Germany

\section{A. B. Gill}

School of Energy, Environment and Agrifood (SEEA), Cranfield University, Bedfordshire, UK ecosystems, many of which have and continue to deliver priceless and indispensable goods and services to mankind. Offshore wind farm development is hence subject to environmental impact assessment and residual impacts should be carefully monitored. Most, if not all, current offshore wind farms are accompanied by an environmental monitoring programme. These programmes should be considered the 'finger on the pulse' to avoid surpassing critical impact levels. They further ensure the achievement of the knowledge base needed to adjust new developments in a scientifically and environmentally sensitive and sound manner.

On 26-28 November 2013, the Royal Belgian Institute of Natural Sciences organised the international scientific WinMon.BE 2013 conference on "Environmental impacts of offshore wind farms: learning from the past to optimise future monitoring programmes" (http:// odnature.naturalsciences.be/winmonbe2013). During the

\author{
H. Lindeboom \\ Institute for Marine Resources and Ecosystem Studies \\ (IMARES), Wageningen UR, Wageningen, \\ The Netherlands \\ D. Wilhelmsson \\ Swedish Secretariat for Environmental Earth System \\ Sciences (SSEESS), Stockholm, Sweden
}


symposium, scientists presented the concluding report of 6 years of research in Belgian offshore wind farms. Belgian and foreign experts complemented the Belgian findings with their knowledge on environmental impact. They particularly aimed at learning from the past to optimise future monitoring programmes. 146 scientists, policy makers and representatives of the wind energy industry from 13 countries (from Estonia to the USA) participated in the symposium.

This Special Issue presents a set of papers presented at the WinMon.BE 2013 conference. These address a wide variety of ecosystem components, from infauna over epibenthos to fish, seabirds and marine mammals. The papers do not only cover observed impacts but also scope for optimising future monitoring programmes. The Special Issue further reflects on the beneficial use of perfected techniques and statistical modelling for data interpretation and sampling programme design. The major lessons learned from the conference are wrapped up in an introductory paper, in which concrete recommendations for designing future monitoring programme are provided.
We sincerely hope that this Special Issue will be inspirational for designing efficient and effective future monitoring programmes. Such programmes are prone not to focus only on a site-specific observation of impacts, but equally on a generic understanding of the ecological mechanisms behind the observed impact. Such approach calls for moving away from individual project-based monitoring programmes to true internationally designed programmes, taking a next step towards an extrapolation of impact assessment to the ecosystem level. This next step is indispensable if we ever want to answer the "so what" questions in offshore wind farm environmental impact assessment.

Acknowledgments We would like to take this opportunity to thank the many people that served the WinMon.BE 2013 scientific and organising committees. We particularly acknowledge the persevered commitment of Robin Brabant, chair of the conference organisation committee, without whom the WinMon.BE 2013 conference would not have been possible. The scientific coordinator, commander and crew of the RV Belgica are thanked for their kind willingness to host the conference participants on an excursion to the Belgian offshore wind farms. 